\title{
Problems and challenges of educational policies in Latin America. The Argentina viewpoint
}

\author{
Francisco Muscará* \\ Facultad de Filosofía y Letras, Universidad Nacional de Cuyo, Argentina \{muscara@ffyl,uncu.edu.ar\} \\ Received on 6 February 2013; revised on 7 February 2013; accepted on 18 April 2013; published on 15 July 2013 \\ DOI: $10.7821 /$ naer.2.2.109-116
}

\begin{abstract}
The objective of this article is to describe the most significant changes which are being carried out in Latin-American educational systems, taking Argentina as a point of reference. To that end, this comparative study tackles the following essential aspects: the principle of equal opportunities and social cohesion; decentralisation of educational systems at an institutional level; educational quality and equity problems; the career of teaching; and financial resources. The reforms carried out at university level have not been analysed, since their complexity exceeds the limits of this article. To conclude, we briefly mention the future goals which have been agreed by those responsible for education in diverse Latin-American countries.
\end{abstract}

KEYWORDS: LATIN AMERICAN CULTURE, EDUCATIONAL POLICY, POLICY ANALYSIS, EDUCATIONAL QUALITY, EQUAL EDUCATION

\section{INTRODUCTION}

In Latin America, the Washington Consensus involved applying privatisation, economic opening and deregulation policies. Those policies were implemented in some cases through plans which were designed by multilateral credit institutions such as the World Bank or the Inter-American Development Bank. Related to the emergence of the "knowledge society" model, the Region experienced the resurgence of human capital theories, which consider education an essential matter regarding the competitiveness of any country. It was considered that investing in the development of people contributed to the development of the whole society. That is why, in 1990, a period of deep transformations started in the Latin-American educational systems. Those transformations were linked to the restructuring processes of the area's regional economies and to the relations established between the State, the society and the market.

However, in the first decade of the 21 st century, a number of political leaders and parties that were more concerned about social issues such as education, assumed the government of some countries and revised the measures which had previously been applied (Bentancur, 2007).

Some years later, in a meeting which took place at El Salvador on May 19th 2008, the Ibero-American ministers for education agreed to drive a project called Educational Goals 2021: the Education We Want for the Bicentennial Generation (Metas

*Por correo postal dirigirse a:

Avenida San Martín 1351- piso $5^{\circ}$-depto. 26. (5500)

Mendoza, Argentina educativas 2021: la educación que queremos para la generación de los Bicentenarios). Their main aim was to "enhance quality and equity in education in order to confront poverty and inequality and, thus, favour social inclusion" (Organización de Estados Iberoamericanos, OEI 2010, p. 9). They considered it essential to deal with unsolved problems: illiteracy (especially in rural areas and among indigenous peoples, women and populations of African origin), early school dropout, child labour, low learning level among students and poor quality of the education offered by states. They also considered the need for incorporating ICTs in the teaching-learning processes and to enhance the development of research and scientific progress.

That way, the policies which had been proposed by the United Nations Economic Commission for Latin America and the Caribbean (UNECLAC) in a document called Education and knowledge: basic pillars of changing production patterns with social equity (1992) were promoted: the need to interrelate educational systems, training, research and technological development. This document set the bases which served as a reference for the transformations which took place in most Latin-American countries.

The main objective was to "create over the next decade (the 90s) certain conditions related to education, training and scientific and technological progress which would allow for the transformation of the Region's productive structures, framed within increasing social equity" (UNECLAC, 1992, p. 16).

Based on that background, this article will try to explain, from Argentina, what has been done in the whole of Latin America during the last two decades with regards to: a) decentralisation of educational systems; b) autonomy in the management of educational institutions; c) increase in the quality of educational programmes; d) training of teaching personnel and e) financial resources. After that, the main goals for the future will be outlined.

This article faces two problems which are difficult to solve:

(1) The heterogeneity of the countries which are being analysed: "America is multiple, heterogeneous, immense, almost infinite... It owns a geographic, historical, political and cultural diversity: it is a multicoloured tile with rough and smooth edges; it is a cloth made of disparate colours and weaves; it is a whole of remnants sewed only by the connecting thread of the Iberian languages" (Mayor, 1995, p. 5). The issues tackled in this article are treated based on Argentina, which is one of the countries with the highest standards of life and education in the region 
(2) The limited capacity Latin-American societies have to generate, spread and apply knowledge: "Certainly, education cannot avoid the complex problems derived from the use and application of knowledge produced in the various spheres related to professional practice and public policies. Moreover, these problems have specific characteristics in our Region" (Gorostiaga, Palamidessi, \& Suasnábar, 2012, p. 13).

\section{EDUCATIONAL REFORMS 1990-2010}

In the last two decades, important transformations have taken place in the Latin-American educational systems. Apart from the new challenges thrown up by the 21 st century, encouraging tendencies of change have become established in the last decade (increase in enrolment, extension of compulsory education, increase in educational budgets, modernisation of management, and incorporation of new technological resources). However, Latin America has not yet been able to successfully solve the chronic efficiency problems of its educational systems, nor has it been able to improve the quality of learning in a solid, equitable way.

This situation reinforces the persistent social inequality in the access and appropriation of systematic knowledge among the different social sectors - something which is an obstacle for the functional democratisation processes of our societies:

More than one third of the population (200 million) live under the poverty threshold and $13.4 \%$ (80 million) live in extreme poverty. Among young people aged 15 to 24 , ten million are unemployed and thirty million work in the informal sector. The R\&D expense of Latin-American productive companies is not significant or relevant at all. Specifically, research continues to be organised in isolation, within traditional disciplines, and in unmodernised, inflexible ways which reproduce systems in which knowledge is fragmented" (Didriksson, 2012).

\subsection{Equal opportunities and social cohesion}

Most Latin-American educational systems were set up at the end of the 19th century, in the period in which national states were being organised. Back then, one of the imperative political objectives was to "build up national union" and "free, compulsory, universal, public" education was considered to be the main instrument which would allow the building up of "social cohesion" and the establishment of the legitimacy of the state and its representatives upon the idea of nation.

A centralised educational system was thought to be able to promote equal opportunities, which is one of the essential objectives of educational politics. Moreover, the elimination of educational inequalities was thought to be able to eliminate other types of inequalities related to the former ones - e.g. social and economic inequalities. Also, if everyone was given the same opportunities, the position each individual reached only depended, theoretically, on each person's effort.

Summing up, this political principle means that any natural, economic, social or cultural disadvantage can be compensated through education. That is why a unique, very prescriptive national curriculum was designed so that its fulfilment could be monitored. The idea that we can all learn the same things, that we behave according to the same norms and that we can be supervised in the same way was considered ideal to build up the concept of "us".

"Building up the national union" is an objective which was present in the origins of the Argentinean educational system and in all the subsequent reforms which were carried out in the 20th century. This objective appears in the Federal Law of Education (Ley Federal de Educación, 1993) and is repeated in the National Law of Education (Ley de Educación Nacional, 2006) which was recently promulgated: "The National State establishes the educational policies and controls their fulfilment in order to consolidate the national union, respecting provincial and local specificities" (art. 5).

Nevertheless, the history of Argentinean education showed that equal opportunities did not necessarily mean equal treatment, so governments realised that efficient education needed to engage the initiative of the provinces and intermediate communities. In a democratic state, equal opportunities mean the construction of a decentralised, pluralist educational system.

School is not expected to be the equalising institution of the 19th century anymore, since education on its own cannot eliminate unfair social and economic disadvantages. Nowadays, it is not necessary to impose a rigid egalitarianism; it is not necessary to advocate a complete levelling out, foreign to the pluralism of democratic societies. The solution to equal opportunities may be found when real fair opportunities are made to be effective, that is, when those with less are given more.

That way, it will be easier to bond individuals through a common project.

In Latin-American countries, the unfair distribution of wealth and knowledge attacks social cohesion. This problem cannot only be solved with improvements in education. Proof of this is the fact that the persistent decrease of illiteracy rates has not been able to eliminate deep social and economic inequalities.

The next table shows the continuous extension of educational systems and the decrease of illiteracy rates in some LatinAmerican countries over the last decade.

Table 1. Extension of educational systems

\begin{tabular}{lcccc}
\hline COUNTRY & $\mathbf{2 0 0 0}$ & $\mathbf{2 0 0 5}$ & $\mathbf{2 0 1 0}$ & $\mathbf{2 0 1 5}$ \\
\hline ARGENTINA & 3.5 & 3.1 & 2.8 & 2.5 \\
BRAZIL & 13.1 & 11.1 & 9.6 & 8.2 \\
CHILE & 4.2 & 3.5 & 2.9 & 2.3 \\
URUGUAY & 2.4 & 2.0 & 1.7 & 1.4 \\
PARAGUAY & 6.7 & 5.6 & 4.7 & 4.0 \\
VENEZUELA & 7.5 & 6.0 & 4.8 & 3.9 \\
LATINAMER. & 11.1 & 9.5 & 8.3 & 7.1 \\
\hline (Cfr. Gentili, 2009, p. 26) & & &
\end{tabular}

In the Region's poorest countries, the school life expectancy doubled in thirty five years (between 1970 and 2005). This situation is similar to that of the two most developed and unfair countries in the continent: Brazil and Mexico" (Gentili, 2009, p. 28).

\subsection{Decentralisation of the educational system}

On behalf of common good and national identity, the state must formulate the basic lines of educational politics, but in order to guarantee the right to education it must organise and promote an educational system in which both publicly and privately managed institutions can participate. I believe that the main role of the state must be to supervise and monitor the educational service, but the design and provision of different pedagogical projects should be carried out with the support of private institutions. This guarantees the commitment of all sectors of society and the right of parents to choose which type of education they want for their children according to their moral or religious beliefs (García Garrido, 2001, p. 42). 
Current recommendations point out the need for organising decentralised educational systems which take into account regional diversity, take care of local needs (appropriateness) and preserve the unity and integration of the system. A decentralised educational service is considered less bureaucratic and therefore capable of providing immediate, adequate solutions for each area and educational unit more easily and rapidly.

The decentralisation proposed should not be understood or put into practice as merely an administrative type of organisation; its main objective should be increasing the autonomy of jurisdictions and institutions so that they can develop more efficiently the objectives of set educational policies. Though in Argentina there is quite a consensus on the advantages that decentralised management provides, there are some threats which should be avoided as much as possible: 1) Educational decentralisation could provoke a loss of coherence in the system. 2) It could lead to a fragmentation of the system. 3) It could increase inequities in the distribution of opportunities (Tedesco, 2001, p. 52).

Between 1978 and 1988, after national primary schools had been transferred to provincial governments, Argentina progressed in the administrative and curricular decentralisation of educational institutions. This process culminated during the government of President Menem, with the promulgation of the Law of Transference (Ley de Transferencia, 1991) when all public educational centres managed by the state, and those which were private but within the official system (from initial levels to secondary non-university levels), became managed by provincial governments.

That policy was ratified by President Kirchner:

The nation state has the principle responsibility - which cannot be delegated - for setting and controlling compliance with educational policy. That policy aims to guarantee the right of all nationals to learn with equal opportunities, with no discrimination whatsoever, and to create an Argentinean society which is fair, autonomous and, at the same time, integrated in the region and in the world. The Provinces and the Autonomous City of Buenos Aires must meet this responsibility of the national state in order to guarantee access to education at all levels, cycles and special schemes for the whole population through the creation, sustainment, authorisation and supervision of all necessary services with the participation of families and communities, as well as those institutions responsible for recognised educational units or authorised privately managed schools (Ministry of Education, Science and Technology (Ministerio de Educación, Ciencia y Tecnología, MECyT, 2006, p.17))

Although that was the general tendency of educational transformations, there were differences between Argentina, Chile and Uruguay, as Argentina transferred those centres with pre-scholar, primary and secondary education and higher vocational training institutes to provincial jurisdictions. Chile developed and improved the market regulatory schema set up in the 80 s by the Pinochet government, and Uruguay applied curricular and management reforms which did not alter the traditional pattern of a "Teaching State" and a centralised administration (Bentancur, 2007).

Institutional management autonomy is the tool through which schools can recover their own cultural mission and can help, based on their own single perspective, shape the cultural identity of their respective societies, which are becoming more and more complex and pluralistic in their composition and orientations.
Recent studies about the fragmentation of the educational system show that learning results do not depend so much on the common educational offer but on the pedagogical project of each educational centre. It should be admitted that formally homogeneous processes give heterogeneous results and national integration and social equity mean eliminating inequalities but not diversity (García Garrido, 2001, p.38).

\subsection{Educational quality and equity}

Based on the economic theory of human capital, states are supposed to consider the educational service as an investment rather than an expense, since a low level of human capital makes physical capital less productive. Social equity is not understood as an external factor of the economic growth process but as a variable which has important effects: social equity must be part of economic growth.

That is why the intention is to universalise not only primary school but also pre-school, incorporating children aged three to five into the formal system, and also, as in Argentina, to extend compulsory school until the last year of secondary education (Ley de Educación Nacional, 2006). In Argentina, a child who enters initial level today will most probably complete sixteen years of education, thirteen of which are compulsory: one year of initial level (at the age of 5); six years of primary school (from 6 to 11); and six years of secondary school (from 12 to 17). As well as that they would probably attend three more years of non-compulsory higher level education: short degrees (two or three years) of vocational training.

It is believed that if universal coverage of basic education is achieved and secondary school is extended, the probabilities of having fewer poor people in the future will increase. However, results are still negative with regards the quality of learning, the appropriateness of the demands of the economic environment and the degree of equity with which they access the different social sectors. Clear signs of the system's inefficiency can be observed, such as the high rates of retakes, delays and dropouts among students.

Regarding effective learning, no Latin-American country has ever achieved a position lower that 33 in the international evaluation tests. An example of that is the fact that the quality assessment tests carried out in Argentina during the last decade warn about the persistence of efficiency problems in secondary school students. In 2007, the tests for Spanish and Mathematics showed an efficiency rate between 58 and $64 \%$ of the total. Though the results for Spanish were higher than the results for Mathematics, both subjects showed a decreasing tendency (MECyT, 2008, p. 18).

Apart from personal frustration, a low academic performance has a negative impact on economic resources: students who lag behind and stay in the system longer than they are supposed to reduce the amount of resources available for students who progress normally. That is why we believe that measures such as increasing enrolment or extending compulsory education are not enough. Emphasis should be put on a quality education which produces learning benefits: knowledge, values and abilities which satisfy the needs of society.

An effective, high-quality education should also provide equity. Thus, there is a proposal called Rich schools for poor people (Escuelas ricas para los pobres). This proposal is the result of a study about the educational quality of Argentinean schools and it confirms the crude reality: "schools attended by 
the poorest students are also the poorest ones" (Llach, 2004, p. 13).

Llach concluded this after analysing the physical capital (facilities and didactic resources), the human capital (training, experience and abilities of the management and teaching personnel) and the social capital (school organisation, school atmosphere, relationship with parents and other institutions of society) of all Argentinean schools based on the data provided by the National Mechanism for the Evaluation of Quality (Operativo Nacional de Evaluación de la Calidad, 2000) for the sixth year of basic education:

We could irrefutably observe through statistical models that there is an ignominious discrimination within the Argentinean educational system, which is not recent at all. In all three capitals, the richest schools are those attended by the wealthiest students. This happens throughout the country but also within each province, both for schools managed by the state and for those managed by private institutions (Llach, 2004, p. 13)

Is educational equity or equal opportunity possible in strongly unequal societies? The attainment of the utopia of an education for all clearly has some analogies with economic growth. A context of growth, especially if it is rapid growth, is really helpful in quickly reducing unemployment, improving the distribution of income and achieving important educational gains (Llach, 2004, p.16)

Other studies have also shown that increases in enrolment and spending on education are not enough to improve the quality indices of basic education:

The experience of this decade allows us to say that the objective of achieving greater social equity through education does not depend only on changes in the pedagogical provisions... If the income distribution patterns are not substantially modified it will be impossible to progress in educational gains (...) (Tedesco, 2001, p. 52).

It is widely believed that equal opportunities in education will be difficult to achieve if educational policies are not supported by changes in the social structures and economic systems.

Comparative empirical studies (UNECLAC, 2005) agree that successful educational policies recommend starting education at the youngest age possible; working systematically with young children to begin teaching them their mother tongue at an early stage; selecting teachers based on their achievements and structure their careers based on that criteria; strengthening the leadership of school directors and encouraging their commitment with pedagogical objectives; adapting educational programmes to learning conditions and to the motivation of students instead of making them follow a uniform curriculum; reducing the management autonomy of schools with unsatisfactory results; giving support to teachers through the provision of important didactical resources: school handbooks, essential titles, videos and computer resources.

First of all, though, it is necessary to have a firm conviction of political authorities, to increase the value of effort and intellectual activities, and to never let levels go down. Compensatory programmes should be extended and "full-time" schools created so that students from poor families can develop their artistic or sporting abilities. With the cooperation of families, students should be required to apply themselves to their studies, and to engage in careful personal presentation and appropriate behaviour.

\subsection{Educational quality and teaching personnel training}

There is no doubt that teaching personnel and their training is one of the factors which most influence the success or failure of any change planned. Teachers can be one of the most positively influential elements in running a school and in students' learning, but they can also present a problem if they are not satisfied with their job. We can certainly say that no educational system will be better than the teaching personnel it has at its disposal.

Only good teachers, dedicated to the task of educating, involved in their job and satisfied with their professional and personal achievements can guarantee the success of social and financial investments.

Unfortunately, recent research (Vaillant, 2009) shows that teachers do not feel appreciated enough by society. They have suffered a progressive deterioration in their quality of life and in most countries their income is among the lowest in comparison with professionals with similar levels of responsibility.

Below, the teaching profession will be analysed through its training and professional practice:

\subsubsection{Training of primary and secondary school teachers}

Initial training of teachers is the first point of access to continuous professional development and plays a key role in the quality and quantity of new teaching personnel. To what extent is the availability of initial training an incentive to attract the best secondary school leavers towards this profession? How does teacher training influence the quality of our systems?

Current programmes of initial and continuous teacher training in Latin America are very heterogeneous and usually have low social prestige. Teaching methodologies have not been updated and little attention is paid to new pedagogic techniques for students from unfavourable contexts or rural areas. That lack is aggravated by the deficient quality of basic and intermediate education which many future teachers have received before entering university or teaching training college.

A distinction must be made between students who are trained to be elementary school teachers and those who are trained to be secondary school teachers. The former attend colleges, where emphasis is placed on didactic learning strategies; most of the latter usually attend university, where emphasis is place on learning disciplinary content (INFOD, 2008).

In both cases a loss of social prestige can be observed compared with other professions. Candidates usually come from a lower socioeconomic strata, they are mostly women who choose a teaching career as a second option, and the requirements needed to enter these types of studies are lower than for other careers.

\subsubsection{Teaching practice in Latin America}

In general, entry, continuation and ascent in the teaching profession in Latin America have common traits:

Ascent depends more on formal aspects (credentials and service period) than on professional achievements; the incentive scheme is not generally linked to performance at school. The pay scale does not take into account different aptitudes, efforts or performance. Apart from that, salaries of Latin-American teachers are lower than those of teachers from other countries which are 
member of the Organisation for Economic Co-operation and Development (OECD).

In Latin America, a long period of professional service is the main element that enables teachers to ascend in their professional career. That career then ends with the position of school director or, eventually, educational inspector - posts in which no teaching is carried out. These are the only posts in which a substantial increase of salary is observed. That means that progress in teachers' careers imply a change of functions, so teachers who want better salaries are obliged to abandon teaching and dedicate themselves to administrative tasks.

Generally, except for the examinations to access managerial roles, there is no evaluation system which stimulates professionals on objective bases, rewarding those with a better performance and obliging those who do not fulfil their responsibilities to be accountable. In Mexico, the application of new evaluation processes has been carried out through examinations assessing knowledge: academic degrees, retraining, professional self-improvement, aptitudes (punctuality and performance), discipline, and service period. Teachers and school directors voluntarily submit themselves to this National Teaching Career Programme (Programa Nacional de Carrera Magisterial), although these types of experiences have often been resisted by teachers' unions (Vaillant, 2009, p. 145).

Reformulating working conditions should be a key element in a new teaching career which, along with a new institutional model, would be able to provide pedagogic authority to professionals. Transforming the teaching career requires teachers to acquire skills related to knowledge of both their own discipline and teaching; cultural skills which allow teachers to appreciate and relate to youth cultures; as well as ethical abilities expressed by their commitment to results, their ability to listen and argue, and their confidence in students' prospects.

The problem of developing the teaching profession is a fundamental requirement of any process of change in education, but we should not forget that teachers are a collective group. School institutions should be the ones to formulate pertinent, quality educational projects. That is why teachers should be able to work as a team in order to provide a single criterion based on institutional aspects.

If we want teachers to commit to the school where they work, it is necessary to stop assigning teachers to schools based on the number of class hours they provide. That way, they would be able to dedicate more time to the schools where they work. In Argentina, for example, there is a proposal to repeat an experience which was carried out during the 70 s, through which secondary school teachers were assigned $12,18,24,30$ or 36 lecture hours in the same school, based only on curricular needs. That calculation included the number of hours dedicated to teaching a subject, but also the number of hours dedicated to student-teacher relations as well as those dedicated to carrying out activities related to the school institutional project. The problem with this type of working contract is that it demands far more economic resources, since teachers are paid for working time at school that is not spent teaching classes.

Educational policies should set an urgent objective: improving teachers' quality of life. Schools and communities should be guaranteed teachers with a strong professional identity who are proud of their career, committed to results, open to permanent training and capable of participating in the processes of change that their local and national communities need.

\subsection{Financial resources for educational quality and educational equity}

At the beginning of the 21 st century, Latin America had around 110 million children aged 5 to 14 , and around 50 million young people aged 15 to 19 . In 22 countries, more than $30 \%$ of the population is of primary or secondary school age (UNECLAC, 2005 , p. 68). These numbers show the magnitude and complexity of the endeavour of running the educational service, due to the number of students, families, workers and institutions involved, as well as the physical, material and financial resources used.

Resources will always be scarce when it comes to achieving significant gains in creating more equal opportunities and a society made up of responsible, well-trained citizens committed to the development of their nation.

Bearing in mind that the region invested 81,900 million dollars in 2000, it is estimated that in order to achieve new goals in quality and equity, around 13,500 million dollars more would be needed between 2005 and 2015, since it is calculated that 150,000 million dollars should have been invested by 2015 (UNECLAC, 2005, p. 31).

Up until now, several options have been developed in order to improve the assignment and use of public financial resources destined for implementing changes:

Increase of the educational budget: For example, in Argentina in December 2005, Law 26075 for educational funding (Ley 26075 sobre financiamiento educativo) was promulgated and it meant an increase of investment in education, science and technology from $4 \%$ to $6 \%$ of the GDP over a five-year period. Subsidy for demand: It uses market mechanisms to fund schools based on the students it has been able to attract and keep in the system ("charter" schools).

Assignment of prices: Based on standardised evaluations which measure the evolution of schools in terms of achievements in the learning of basic abilities in Spanish and Mathematics, stimulating their management and teaching in order to reinforce students' learning.

Inter-scholar abilities: Through this measure, low-scale projects are funded. They are designed and implemented by management and teaching personnel who are responsible for the impact of assigned resources.

Distribution of expenses by educational level: Higher level students are more expensive than primary level students and can generally contribute to the expenses of their education.

Direct transference to families with scarce resources: In Argentina, for example, some programmes have been recently implemented to give economic assistance to those families with school-age children ("universal assignment per child"). These programmes may sometimes also offer additional subsidies to pay for transport and material acquisition expenses (UNECLAC, 2005).

In addition to these resources, there is the private expense which, in most Latin-American countries, exceeds the GDP percentage that private institutions assign for the same objective in the ODCE countries. Families contribute to the expenses associated with school attendance (books, transport and school uniform), as well as paying taxes. Add to this the fact that some of their children could be working but are not because they are studying. However, such contributions are probably largely coming from families with a middle-high socioeconomic status, whose children are generally assessed with better learning 
performances. This situation can contribute to an increase in the breach in educational achievements based on the social stratum of students' families (UNECLAC, 2005, p. 46).

Furthermore, when funds are being collected, it is essential to involve business owners in school matters, in carrying out projects for improvement, in giving support to the implementations of curricular reforms and in reinforcing vocational aspects.

In the future, business owners will be the main beneficiaries when they search for capable workers who are able to adapt to technological shifts. That is why it is so important to establish bonds with the productive sector; they can contribute to the sustainment of vocational schools. Also, from an academic viewpoint, the productive sector can suggest certain contents to be taught in order to achieve a better articulation between the educational and labour worlds. Latin America still has a long way to go in that sense.

\section{CONCLUSIONS: GOALS FOR 2021}

In El Salvador in May 2008, the Ibero-American ministries for education assumed a collective commitment to achieving educational goals and carrying out the essential social transformations which would allow those goals to be accomplished. The policies contained in the project called Educational Goals 2021: the Education We Want for the Bicentennial Generation, which were ratified in a meeting celebrated two years later at Mar del Plata, Argentina, call for the implementation of a set of programmes to facilitate their goal, something which will only be possible if each country makes a sustained effort and gives support to its neighbours.

The objectives are enormously ambitious: improving educational quality and educational equity to confront poverty and inequalities and thus favour social inclusion. The idea is to tackle decisively once and for all those challenges which have not yet been solved: illiteracy, early school dropout, child labour, students' low performance and low quality of public education.

The intention is to fulfil these objectives with a willingness to confront the demands of the information and knowledge society: the incorporation of ICTs to education and learning, the promotion of innovation and creativity and the development of research and scientific progress.

Out of all those lines of action, we want to highlight the following, which are directly related to the issues outlined in this document:

\section{Regarding the human right to education:}

Some aspects which have been debated about for decades in various countries, such as the increase of educational coverage and equal opportunities, continue to be debated and efforts are still being made to tackle them. An important part of that process is formed by projects developed in different countries which aim to incorporating more children into education from a pre-school level; Mexico and Colombia stand out for having carried out the highest number of successful projects of this type. Others emphasize retention in schools; Brazil is the country with most experience in this area. Other types of projects create opportunities for secondary education and facilitate educational processes through distance education both for teachers and students who live in areas which are difficult to access. There are compensatory programmes which pay special attention to the poorest sectors of society, and projects which enhance bilingual and multicultural education, which facilitates education for the indigenous population while respecting their own culture. Uruguay and Mexico present positive experiences in this last issue.

- Programme for early childhood support: establishing communication channels among all countries in the region and developing a network of project managers who articulate initiatives, actions and strategies for early childhood.

- Programme for literacy and permanent education: implementing intensive projects and actions aimed at the most neglected, vulnerable sectors.

- Programme to give support to diversity: promoting training in specific abilities for civil servants and teachers dedicated to intercultural, bilingual teaching.

- Programme for technical, vocational education: promoting the development of entrepreneurial skills in students in order to favour their personal autonomy and occupational integration.

\section{Regarding the promotion of social cohesion:}

"Social cohesion" is understood as the dynamic ability of a given society to generate a legitimate structure of distribution of its material and symbolic resources at a socioeconomic level (welfare), at a sociopolitical level (rights) and at a sociocultural level (recognition) through the interaction and assignment mechanisms belonging to a given democratic state, market, civil society and community. In fact, this concept of "social cohesion" is the goal of a long process of national societies in which civil, political and social rights have been generalised and framed within the beliefs of all members of those societies.

- Programme for education in values and citizenship: promoting topics related to the culture of peace, the environment, sports, arts and health.

- Programme for citizenship, culture and arts education: promoting a network of music and arts schools in order to favour social and cultural integration.

\section{Regarding schools' autonomy of management:}

Educational institutions and organisations obtaining quality results and the highest marks in national and international tests have clear strategic and meaningful objectives, make the most of their resources and are continuously improving through systematic processes of learning and reflexion. Nevertheless, in order to improve or maintain significantly high levels of performance, all institutions, no matter their nature, can learn from their own or others' experiences, maximising what they are good at, that is, learning efficient practices while achieving their goals.

González (2005) states that "good practice" is defined as:

An experience which solved a problem or met a social demand through novel methods or mechanisms, with the participation of different parties, obtaining demonstrable results which are better than those of other similar organisations and which have lasted in time and can be replicated by other organisations (Quoted by Cardona, 2010, p. 88)

- Programme to improve the governability of educational institutions: implementing the exchange of successful 
experiences in management and supervision among schools and authorities.

\section{Regarding the excellence of the educational service:}

Between 2004 and 2008, a study was carried out in 16 LatinAmerican countries and the Caribbean entitled Second Comparative, Explicative Regional Study (Segundo Estudio Regional Comparativo y Explicativo (Serce)). It was developed by the Latin American Laboratory for Assessment of the Quality of Education (LLECE) and its main objective was to generate knowledge about the process of learning Mathematics, Spanish (reading and writing) and Natural Science of third and sixth grade students in primary school (in Colombia, sixth grade is part of secondary school). It showed that an atmosphere of respect, motivation and varied communication using a range of tools is crucial to students' academic performance (Cardona, 2010, p. 95).

The results of this study reaffirm those carried out at a global level by highlighting once again the crucial role of teachers: how their preparation and communicative abilities play a vital part in achieving effective results for the improvement of education. That is not only due to the communicative processes which take place inside the school, but also because teachers are those who generate the respectful, friendly, positive environment which is key to promoting learning among students. Furthermore, this research shows that the atmosphere of the school and its average socioeconomic and cultural level are important variables in explaining students' performance.

Another comparative study carried out by McKinsey \& Company (2007) found that successful educational systems have three common features:

- They have the most capable people providing teaching (the quality of an educational system greatly depends on the quality of its teachers).

- They trained those people until they became efficient teachers (the only way to improve results is to improve the institution).

- They implemented specific support systems and mechanisms to guarantee that all children were able to obtain the benefits of an excellent education (the only way for the system to achieve a better performance is to elevate the standards of all students) (Quoted by Cardona, 2010, p. 92).

Here, again, one can observe the crucial role teachers play in obtaining good learning results.

\section{Regarding the use of new technological tools.}

Teachers who are able to use ITCs develop effective strategies to work autonomously. Training in this field changes the patronising, passive view of teacher training, allowing them to be creative and to design and adapt activities, methodologies and materials to their subjects and specific working contexts.

Teachers who use ITCs to prepare creative class material with video, audio, pictures or examples are more than creators of materials; they become designers of learning strategies and protagonists of the educational processes (Cardona, 2010, p. 96).

- Programme for the improvement of educational quality: eliminating (in students and teachers) existing inequalities with regards the use of ITCs and incorporating this resource into the teaching process of all subjects.

- Programme for reading and libraries: promoting reading and the use of libraries among children, young people and adults. Integrating reading and writing into the learning process of all subjects.

- Programme for evaluation of education: creating a culture of evaluation which permits the generation of realistic reports based on the governmental and institutional objectives set. Developing evaluation models for students and teachers.

\section{Regarding teacher training:}

The best educational systems have implemented mechanisms which are more efficient in the selection of candidates for future teaching training that the systems with low performances. These systems are well aware that a bad choice in that selection can lead to forty years of bad education. Those mechanisms assume that for a person to become an efficient teacher they should possess certain identifiable characteristics before carrying out their profession: high levels in language and arithmetic, strong interpersonal and communicative abilities, interest in learning and motivation in teaching. Learning happens when students and teachers interact with each other; that is why an improvement in learning entails an improvement in the quality of that interaction.

- Programme for training of teaching personnel: offering support to new teachers and further training to teachers who are already working.

- Programme for the promotion of the Ibero-American area of knowledge: contribute to the mobility and construction of academic and research networks.

Bearing in mind these "goals" we should ask ourselves if we are proposing an alternative model of educational policies to that of the 90s. Our answer is the following:

Up until now, that question has no concluding answer, since we are comparing governmental actions with different degrees of implementation and evaluation. Reforms started in the 90s have shown their effects and have been widely analysed. However, plans -due to their own nature- express desirable objectives and strategies which are uncertain since they belong to the future. That is why, currently, we can only check if the implemented policies correspond to the programmes which had been planned. That should make us cautious in our analysis. (Bentancur, 2010, p. 14).

The experiences we have described, these "good practices", are not meant to be used as a manual of "models" for educational institutions. Each successful practice has its own dynamic history, with its ups and downs, and will probably not be able to be reproduced literally in a context with different features. However, it shows the creativity and spirit needed to solve the educational problems of a certain region. Likewise, it is an indicator of the various alternatives which can be implemented and which may prove enlightening to all those who are determined to reform and programme educational improvements. 


\section{REFERENCES}

Bentancur, N. (2007). ¿Hacia un nuevo paradigma en las políticas educativas? Las reformas de las reformas en Argentina, Chile y Uruguay. Revista Uruguaya de Ciencia Política, 16, 159-179. Montevideo: Universidad de la República.

Bentancur, N. (September, 2010). El "derecho a la educación" como nuevo concepto estelar de las políticas educativas en América Latina. Paper presented at the Congreso Iberoamericano de Educación: Metas 2021, 13-15. Buenos Aires. Retrieved from nicobent@ffcs.edu.uy

Cardona, A. (2010). Impacto de las prácticas de política educacional para mejorar la calidad de la educación en América Latina y el Caribe. Actualidades Pedagógicas, 55, 87-97. Universidad Pedagógica Nacional de Colombia.

Didriksson, A. (November, 2012). Elementos de construcción de la nueva agenda universitaria. Paper presented at the III Congreso Latinoamericano de Prospectiva: Prospecta América Latina, 1 y 2 de noviembre. Mendoza: Universidad Nacional de Cuyo. Retrieved from de www. rectorado.uncu.edu.ar

García Garrido, J. L. (2001). Perspectivas de la educación en Europa en el siglo XXI. In M. Lázaro (Ed.). Problemas y desafios para la educación en el siglo XXI en Europa y América Latina (pp. 29-46). Universitat de València.

Gentili, P. (2009). Marchas y contramarchas. El derecho a la educación y las dinámicas de exclusión incluyente en América Latina. Revista Iberoamericana de Educación, 49, 19-59. Madrid: OEI.

González, A. (2005), Manual operativo del Banco de Buenas Prácticas de Cooperación Empresarial con el Sector Educativo. Bogotá: Fundación Empresarios por la educación.

Gorostiaga J., Palamidessi, M., \& Suasnábar, C. (comps.) (2012). Investigación educativa y política en América Latina. Buenos Aires: Noveduc.

Llach, J. J. (2004). Escuelas ricas para los pobres. In Boletín de la Academia Nacional de Educación, 57, (pp.13-21). Buenos Aires.

Mayor, F. (1995). Prólogo. In E. Schiefelbein \& J.C. Tedesco (Eds.), Una nueva oportunidad. El rol de la educación en el desarrollo de América Latina, p. 5. Buenos Aires: Santillana.

McKinsey \& Company (2007). How the world's best-performing school systems come out on top. McKinsey \& Company social sector office.

Ministerio de Educación, Ciencia y Tecnología (1991). Ley de transferencia de los servicios educativos (Num. 24049). Buenos Aires: Imprenta Oficial

MECyT (1993). Ley Federal de Educación (Num. 24195). Buenos Aires: Imprenta Oficial.

MECyT (2006a). Documento para el debate: Ley de Educación Nacional. Hacia una educación de calidad para una sociedad más justa. Buenos Aires: Imprenta Oficial.

MECyT (2006b). Ley de Educación Nacional (Num. 26206): Hacia una educación de calidad para una sociedad más justa. Buenos Aires: Imprenta Oficial.

MECyT, Consejo Federal de Educación (2008). Documento preliminar para la discusión sobre la educación secundaria en la Argentina. Buenos Aires: Imprenta Oficial.

MECyT, Instituto Nacional de Formación Docente (INFOD, 2008) Hacia un acuerdo sobre la institucionalidad del sistema de formación docente en la Argentina. Buenos Aires: Imprenta Oficial.

Organización de Estados Iberoamericanos, OEI (2010). 2021 Metas educativas. La educación que queremos para la generación de los bicentenarios. Madrid: OEI.

Tedesco, J.C. (2001). Educación y nuevo capitalismo en América Latina. In M. Lázaro (Ed.), Problemas y desafios para la educación en el siglo XXI en Europa y América Latina (pp. 47-57). Universitat de València.

Tiana Ferrer, A. (2001). Logros y desafíos de la educación al inicio del siglo XXI. In M. Lázaro, (Ed.), Problemas y desafios para la educación en el siglo XXI en Europa y América Latina (pp. 11-27). Universitat de València.

United Nations Economic Commission for Latin America and the Caribbean (UNECLAC, 1992). Education and knowledge: basic pillars of changing production patterns with social equity. Santiago de Chile: United Nations.

United Nations Economic Commission for Latin America and the Caribbean UNECLAC/UNESCO (2005). Investing better in order to invest more. Financing and management of education in Latin America and the Caribbean. Seminarios y Conferencias Series, 43. Santiago de Chile: United Nations.
Vaillant, D. (2009). La profesión docente: lecciones para diseñadores de políticas sobre reformas que funcionan. In S. Schwartzman \& C. Cox (Eds.), Politicas educativas y cohesion social en América Latina (pp. 131-175). Santiago de Chile: Uqbar. 